\title{
Use of Learning Resources at McMaster University
}

\author{
V. R. NEUFELD, W. B. SPAULDING
}

To appreciate our first three years' experience with a range of learning resources in the faculty of medicine at McMaster University in context it is necessary to understand the educational foundation on which the programme is based. ${ }^{12} \mathrm{~A}$ list of these principles would include self-directed learning balanced by learning in a small group tutorial setting. For both environments a wide range of learning resources are available.

\section{The Users}

The prime user is, of course, the student himself. Since our students come to the programme from a wide variety of academic backgrounds (roughly one-third have little or no biological sciences in their previous university experience), the information needs of students vary greatly. Just as varied are their individual learning styles. It is the role of the tutor (the faculty member responsible for a small group of students) to help the individual student define his personal objectives, using the general objectives of the current unit and of the three-year programme as a guide. An example of a general programme goal is critical thinking or problem-solving ability-a learning objective which the student would approach in many ways throughout the three-year programme. The tutor also helps the student to discover how he learns most efficiently, telling him about the most suitable learning resources and events. Finally, the student must learn to evaluate his own learning progress with reference to his stated goals and with help from his tutor and his peers.

The tutorial group is both a user of learning resources and a resource in itself. The small group setting allows the students to profit from each other's varied experiences. Thus, a tutorial group discussing the problems of a patient with asthma may have a sociology student comment on the effects of the illness on the family, a mathematician sort out some epidemiological data, and a student with a chemistry major enlarge on the biochemical aspects. Moreover, the students learn to become sensitive as members of a group, perceiving its interaction and appreciating that group problem-solving activity may sometimes be more productive than the sum of the individual efforts.

The faculty unit planners determine the needs for learning resources for particular units, review and revise those resources already available, and prepare or purchase new materials. A planning group includes faculty members from several disciplines as well as the students. A medical editor and several audiovisual professionals help unit planning groups in evaluating and preparing the learning resources, which are outlined in a unit handbook prepared by the planners.

\section{Learning Resources for Information}

These resources can be classified into three groups: readings, audiovisual resources, and resource faculty.

\footnotetext{
Department of Medicine, McMaster University, Hamilton, Ontario, Canada

V. R. NEUFELD, M.D., F.R.C.P.(c), Assistant Professor

W. B. SPAULDING, M.D., F.R.C.P.(c), Professor
}

The printed page remains the chief source of information. A book is readily available, portable, versatile, and relatively inexpensive. Information can be found quickly and read at any speed; the reader can skip irrelevant sections, repeat difficult parts, and look at illustrations or tables only. For flexibility and efficiency the printed page is unsurpassed as a learning resource. In the McMaster programme a wide range of selected readings is made available for students. For example, in any 10-week unit, copies of appropriate reviews in journals can be borrowed from the library for overnight use. Specific pages or chapters in textbooks and monographs are indicated in the unit handbooks and are made available in the reserve shelves of the health sciences library. Rather than recommending standard textbooks for purchase, students are advised to use several books before deciding which they will purchase for their own use. The students are making increasing use of the library photocopying services.

The lecture has been largely abandoned as a method of giving information. There are a variety of sessions where larger student groups hear some sort of presentation. These are described beforehand, so that the student can decide whether or not the session will meet his educational needs. These sessions occur no more often than one a day, often only once or twice weekly, and are planned only if this format is the best way of achieving a particular educational purpose. Examples include lectures by visiting professors, panel discussions, presentations of patients with unusual clinical features, and laboratory demonstrations. Sometimes these events are videotaped so that they can be reviewed later or used by students who are unable to attend the session. Recently, students have prepared clinical-pathological conferences where members of one group are the discussing clinicians and others present the laboratory and pathology aspects of the case.

\section{AUDIO-VISUAL RESOURCES}

A wide range of these resources are available-predominantly the slide-tape presentation, of which there are nearly 600 , most of them produced locally and prepared by appropriate faculty members at the requests of unit planners with the help of a medical editor, photographers, and graphic artists. Increasing experience is teaching us that a slide/tape sequence may be unnecessary and too expensive to produce if the same information can be provided in a reading. Some slides/tapes have accompanying work booklets with "pre" and "post" tests, or responses of other kinds. Students prefer those presentations which encourage them to participate actively, to think critically, and to anticipate feedback. Some students use the slides/tapes as an introduction or a review to a subject, others as a major information source, some only when a particular problem is being pursued, and some do not use them at all. The specific use of these resources depends on the authors' objectives, as well as the need of a particular student on any one day. Some students use them as a means of varying their learning experience. Audiovisual modules are located in the library, in various parts of the health sciences centre on the university campus, and in all the participating teaching hospitals in the city of Hamilton (see fig. 1). 


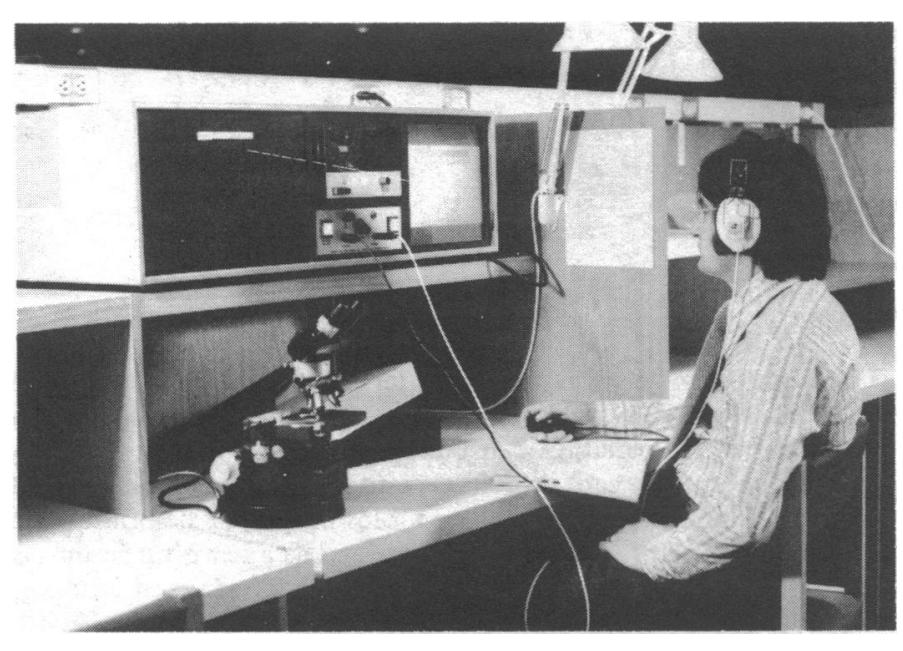

FIG. 1-A learning module in use.

Other resources include audiotape cassettes, both those prepared locally and those purchased from commercial agenciesfor example, the Audio-Digest series. Often various combinations of scripts, slides, audiotapes, and films are used. Many videotapes are available which show physiology demonstrations, interviews with patients, or lectures by visiting professors. A wide range of morphology demonstrations have been prepared by a faculty group including anatomists, radiologists, morbid anatomists, and clinicians. Examples are plastic-embedded pathology specimens, plastic or plaster models, $x$-ray films, illustrated charts and displays, and predissected anatomical specimens (see fig. 2). The latter include "programmed cadavers" dissected to illustrate certain morphological principles.

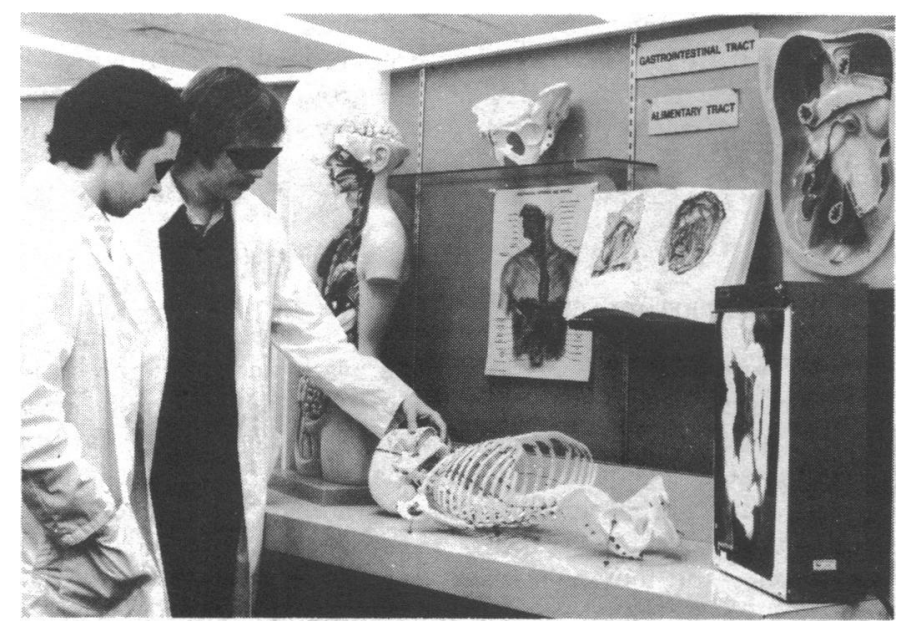

FIG. 2-Anatomy display.

Most of these audiovisual resources are available in the health sciences library. They may be moved to a "learning laboratory," where they are available throughout the 24 hours. While most of these materials have been designed for undergraduate education programmes, others are made for teaching residents and for continuing education as well.

\section{RESOURCE FACULTY}

The resource person is a faculty member who, like a consultant in a clinical practice, contributes his specialized knowledge to a student or group of students when a particular learning problem arises. Before contacting him students are expected to have explored the topic in their individual reading and study, or in a tutorial group.

\section{Learning Resources for Problem Solving}

It is somewhat artificial to make a distinction between learning to acquire information and learning to apply that information to problem solving. This is all the more true in the McMaster programme, where problem-based learning is a fundamental educational approach. This emphasis results in increased retention of information, is more motivating and enjoyable to students, enhances critical thinking, and more closely resembles "real life learning." Increasingly, problem situations have become the focus for learning in our programme. By first attempting to define the dimensions of a problem, a student is more aware of what information he needs and can proceed to get it. To encourage this type of problem-based learning, several kinds of additional learning resources are available.

\section{PATIENTS}

McMaster students are introduced to patients early in their course and get an increasing opportunity for direct contact with them throughout the three-year curriculum. Initially, these student-patient encounters are highly supervised. Students are encouraged to focus their studies on the problems of patients, and often these problems are presented by a student to his tutorial group. Patients are seen both in hospitals (including visits to the emergency department), in general practice, and with clinical teams of health professionals in ambulatory clinics.

\section{SIMULATED PATIENTS}

Because actual patients may not always be available at a given time and place, or for a specific purpose, we have increasingly turned to the use of simulated patients. These are normal persons who have been trained to simulate the clinical features of an actual patient. Rather than use trained actors, we employ lay persons who are versatile and teachable. ${ }^{3}$ In addition to giving an accurate and realistic medical history, a simulated patient can be trained by a clinician to mimic a wide range of physical signs-for example, exaggerated tendon reflexes, extensor plantar responses, abdominal rebound tendernessand various emotional and psychiatric states. This requires considerable experience and time on the part of the cliniciantrainer with both the initial preparation of the "programme" and in maintaining its quality, but this particular resource has been of great value for both learning and educational research, where the patient presentation can be kept reasonably "constant."

\section{“PROBLEM BOXES"}

Here, a particular clinical problem is "captured" by various audiovisual methods and packaged in a portable and flexible format. An attempt is made to select the medium that most realistically portrays the problem. Rather than a paper summary of a medical history, an audiotaped interview of the actual patient (or a simulated patient) is made available. To present mental status or emotional problems, or movement disorders, a videotape or a moving picture cassette is prepared. Many other inclusions are added such as mini $x$-ray films, photographs, $35 \mathrm{~mm}$ pathology slides, and reproductions of actual laboratory investigations or electrocardiograms. An accompanying student's work booklet serves as a self-study guide. The student may 
write up a medical record with progress notes as he works through the problem. The problem box has also proved to be a useful learning resource at a small group tutorial.

\section{COMPUTER-BASED PROBLEM SOLVING EXERCISES}

A series of physiological models are available in a computer format, one each for cardiovascular physiology ("McMan"), respirology ("McPuff"), renal physiology ("McPee), and pharmacology ("McDope"). The student is presented with basic clinical data about his "patient" and may ask for further clinical or investigative information. He then proceeds to administer various forms of treatment and receives feedback about the physiological and clinical effects of his manipulations. Again, this resource is useful for both individual and small group learning settings.

\section{Assessment of Learning Resources}

Various methods have been used to assess the educational effectiveness, technical quality, and acceptance of all of these learning resources. Some of the following generalizations can be made from these studies: there is a wide range of study patterns among students; for the acquisition of information, readings are the most extensively used resource; as students progress through the programme, they become more discriminating and efficient in selecting and using various resources; resources which provide problems and require active thinking and participation are preferred to those where the student just sits and listens. Increasingly, it is being realized that user acceptance is a valid measure, for unless the resource is used it is educationally worthless.

\section{Relevance of Learning Resources to Medical Practice}

We believe that medical students who become independent and efficient self-directed learners during their undergraduate careers will maintain their own continuing education throughout their professional careers. Moreover, several of the learning principles arising out of the undergraduate experience at McMaster can be applied to the qualified doctor. No learning resource is effective unless he himself is also an efficient, selfdirected learner, able to define problems precisely, and to go to the information source which most adequately meets an educational need. Cyril Houle, the American educator, has suggested that the most appropriate educational stimulus is the professional situation itself-in the case of the physician, this stimulus is the problem of his patients. ${ }^{4}$ Perhaps before rushing to repetitive continuing education conferences, or acquiring complicated educational audiovisual facilities, the physician should be helped to develop those resources which are already available and which may well be the most effective. These include his own critical thinking ability, his patients as an educational stimulus, and his personal or hospital library.

Many individuals, both students and faculty members, have been and continue to be involved in the conception, growth, and development of learning resources at McMaster. Additionally, several colleagues made valuable suggestions for inclusion in this paper. The help and co-operation of all these persons is hereby acknowledged.

\section{References}

1 Spaulding, W. B., Canadian Medical Association fournal, 1969, 100, 659. Spaulding, W. B., Journal of the Royal College of Physicians of London, $1972,6,352$.

3 Barrows, H. S., Simulated Patients, Springfield, Thomas, 1971.

4 Houle, Cyril O., Medical Clinics of North America, 1970, 54, 5.

\section{Failure to Produce Semen at Ejaculation}

What might be the cause of failure in a man of 36 to produce semen after otherwise normal sexual intercourse, including a sensation of ejaculation? There is a history of a ruptured scrotum with subsequent infection at the age of 26.

If this patient is able to achieve an erection and orgasm but no semen is emitted then there is a blockage in the region of the ejaculatory ducts, or destruction of the seminal vesicles (which contribute the major part of the seminal volume), or the semen which is being ejaculated is passing back into the bladder because of an associated failure of the bladder neck musculature to contract at the moment of orgasm. Blockage of the ejaculatory ducts may have occurred as a result of the injury if the prostatic urethra was seriously lacerated or in consequence of scarring later on. This and any pathological process in the seminal vesicles can be demonstrated radiographically by injecting water-soluble contrast medium towards the bladder through the exposed vas deferens. Retrograde ejaculation may occur as a congenital abnormality or in consequence of any surgical operation on the neck of the bladder and can be demonstrated by finding spermatozoa in the urine passed after ejaculation. If this is the case, these spermatozoa may be recovered from the centrifuged urine and used in artificial insemination. It is difficult to see how any of these changes could have been caused by an injury which was limited to the scrotum alone-unless the urethra or neck of the bladder was also seriously damaged.

\section{Face Masks to Check Spread of Influenza}

Can the use of face masks as a public health measure help to prevent the spread of influenza in urban areas?

There is no doubt that influenza virus is spread in airborne droplets expelled in respiratory secretions by infected persons. Face masks might afford some protection to individuals forced by travel in crowded buses or trains to come in contact with people excreting virus by coughing and sneezing. Whether it is practicable to recommend their use as a public health measure is doubtful. The wearing of face masks by people with colds or nasal catarrh not only causes discomfort but possibly increases the spread as masks must be handled, removed, and replaced when the nose is blown and dissemination could be increased in this way. 